\title{
Prof. Christoph J. Raub celebrates his
}

\section{5th Birthday}

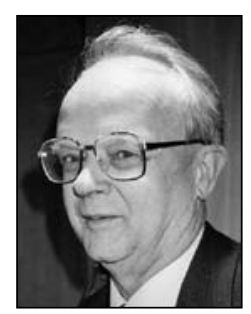

It is 5 years since we reported on the $80^{\text {th }}$ Anniversary celebrations of the German Precious Metals Research Institute, FEM, in Schwäbisch Gmünd, Germany (Gold Bulletin, 35 (4), p133-4, 2002) and the role played by Professor Christoph J. Raub, its former director. This year sees Prof Raub celebrating his $75^{\text {th }}$ birthday and we offer him our heartiest congratulations.

Chris Raub has been a staunch supporter of Gold Bulletin since its inception and has contributed frequently over its 40 years. Although now retired, he currently serves on the Technical Advisory Committee of Gold Bulletin and is still very active, pursuing a range of interests, particularly in the historical aspects of the precious metals.

The Editor

\section{Publications policy: papers are now requested for publication}

At the beginning of the year, we noted in my Editorial that we had been overwhelmed with papers, particularly those from the GOLD 2006 conference, and that our publication policy had been modified accordingly. You will have noticed that each issue this year is much larger than usual to improve our service to you, our readers, and also to reduce this backlog. This temporary policy change may have resulted in fewer of you submitting papers for publication in Gold Bulletin.

The Editorial team would like to make clear that the backlog of papers is now almost cleared and that we are resuming our normal publications policy. Therefore, we welcome offers of papers for publication and would particularly encourage papers in the fields of catalysis durability and applications, nanotechnology and its applications, gold chemistry for biomedical and electronic uses and materials science and applications. Details of how to submit papers are given on the contents page and on our website, www.goldbulletin.org. We can offer prompt publication once again.

The Editor 